\title{
Correspondence
}

\section{Tonometer Testing Station}

\section{To the Editorial Committee of the British Journal of Ophthalmology}

SIRs, A station for the testing of tonometers run by the Ross Foundation with the support of the Faculty of Ophthalmologists has functioned in Edinburgh for almost 20 years. Owing to the increasing use of applanation tonometry and the fact that the methods of inspection and standardization of Schiötz tonometers are now well established and generally accepted, it is proposed to close the Edinburgh Tonometer Testing Station which was originally established on a research basis. The publication of this letter will, I think, help more than anything else to explain the position $\mathrm{G}$ to the members of the profession.

THE ROYAL INFIRMARY

Yours faithfully,

PRINCESS ALEXANDRA EYE PAVILION

C. R. S. JACKsON

CHALMERS STREET

EDINBURGH EH3 9HA

January 12, 197 I

\section{Book reviews}

Stereoscopic Manual of the Ocular Fundus in Local and Systemic Disease. Vol. 2. By F. G. Blodi, L. Allen, and O. Frazier. 1970. Pp. $135+$ ix, 112 pairs of stereo transparencies with viewer, 53 figs. Mosby, St. Louis; Kimpton, London. (£ 17.75$)$

Although ophthalmologists are well aware of the advantages of stereoscopic vision, many are content $\stackrel{\text { }}{\xi}$ with uniocular views and illustrations of the fundus. This superb production should help to convince $O$ them that the extra time, trouble, and expense required for stereoscopic fundus photography are well worth while. The sixteen reels, each containing stereo-photographs in colour of seven fundus conditions, can be viewed with the folding viewer supplied and provide impressive illustrations of the normal fundus, congenital anomalies, degenerative changes, diseases of the optic nerve and macula, retinopathies associated with systemic disease, and inflammatory, neoplastic, and traumatic ${ }_{0}$ conditions. The photographic techniques used are described in detail and there is a useful chapter $\mathrm{c}$ on the interpretation of fluorescein angiograms.

The main text contains clinical details of the patients whose fundi are illustrated in the photographs, and makes more interesting reading than a conventional textbook description. In many cases fluorescein angiograms are included with the text and demonstrate the additional features of diag- $\rightarrow$ nostic importance that can be derived from this technique.

The high price of this manual will preclude many students from buying it, but it should certainly $\stackrel{\text { }}{\mathbb{D}}$ be available wherever ophthalmology is taught, and a thorough study of the photographs will make an excellent introduction to the study of fundus abnormalities. 